\title{
KNOCKDOWN FACTORS FOR TWO KINDS OF STIFFENED CYLINDERS UNDER AXIAL COMPRESSION
}

\author{
BIN JI ${ }^{1,2}$, HAO LI ${ }^{1}$, HAN HAN ${ }^{1}$, XING ZHANG ${ }^{1}$, AND CHUNLEI WU ${ }^{1}$ \\ ${ }^{1}$ Aerospace System Engineering Shanghai \\ ${ }^{2}$ Shanghai Key Laboratory of Spacecraft Mechanism \\ 201109, No. 3888, Yuanjiang Road, Minhang District, Shanghai, China. \\ E-mail jibin6@163.com
}

Key words: Knockdown Factor, Stiffened Cylinder, Imperfection, Isogrid, Orthotropic grid, Axial Compression.

\begin{abstract}
Stiffened cylinder is widely used in launch vehicle structures because its stiffener can prevent buckling wave to spread in the skin. However, it is still sensitive to shape imperfection more or less. Knockdown factors of stiffened cylinders have been researched all the time. However, comparison among different grid types is seldom. In this paper, both orthogrid stiffened cylinder and isogrid stiffened cylinder under axial compression are studied. Linear eigenvalue method and nonlinear implicit method are adopted to calculate the bearing capacities of the cylinders with ABAQUS. The sinusoidal function is used to model the imperfection. Given different imperfection parameters, the sensitive of bearing capacities to the shape imperfection is researched for two kinds of cylinders. Axial compression experiments are also implemented for the stiffened cylinders, and the results agree with numerical result. Knockdown factor of orthogrid cylinder is about 0.5 0.7. Meanwhile, it proves that when the stiffener is strong enough, the effects of shape imperfection on load capacity can be ignored for orthotropic grid, and its knockdown factor is nearly 1.
\end{abstract}

\section{INTRODUCTION}

Most primary structures in launch vehicle are thin-walled cylinders, such as tanks and interstage skirts. In 1940s and 1950s, unstiffened cylinder is first applied in aerospace engineering. However, many experiments revealed that its axial compression bearing capacity was very sensitive to manufacturing imperfection. When the radius-to-thickness rises to 1000 , knockdown factors of bearing capacity could even be less than 0.2 .

In order to describe the sensitivity of thin-walled cylinders, knockdown factor is defined as the ratio of actual bearing capacity to theoretical bearing capacity. Many scientists gave the lower bound curves of scatted experiment data as knockdown factor. The most famous one is the report NASA SP-8007, which has been used as for many years[1].

$$
\gamma=1-0.901\left(1-e^{-\Phi}\right)
$$




$$
\Phi=\frac{1}{29.8}\left[\frac{R}{\sqrt[4]{\frac{D_{x} D_{y}}{E_{x} E_{y}}}}\right]^{1 / 2}
$$

Many experiments have proved that NASA SP-8007 may be too conservative[2,3]. In recent years, many countries and corporations restarted to study this problem based on advanced measurement and algorithm, such as NASA, ESA and China. Wagner et al. [3] defined the local buckling load as the ultimate load of thin-walled cylinders and obtained the knockdown factors as:

$$
\begin{gathered}
\gamma=\Omega \cdot(R / t)^{-\eta} \\
\Omega \approx-0.0196 \cdot\left(\frac{L}{R}\right)^{2}-0.0635 \cdot\left(\frac{L}{R}\right)+1.3212 \\
\eta \approx-0.013 \cdot\left(\frac{L}{R}\right)^{2}+0.061 \cdot\left(\frac{L}{R}\right)+0.08
\end{gathered}
$$

Some researchers think that $L / R$ is also important to determine the bearing capacity of cylinders. Therefore, they considered both $R / t$ and $L / R$ into the knockdown factors. For example, Evkin [4] proposed the following fitted equation according to large amount of experiments:

$$
\gamma=1.23 \cdot Z^{-0.138}, \quad 50 \leq Z \leq 7000
$$
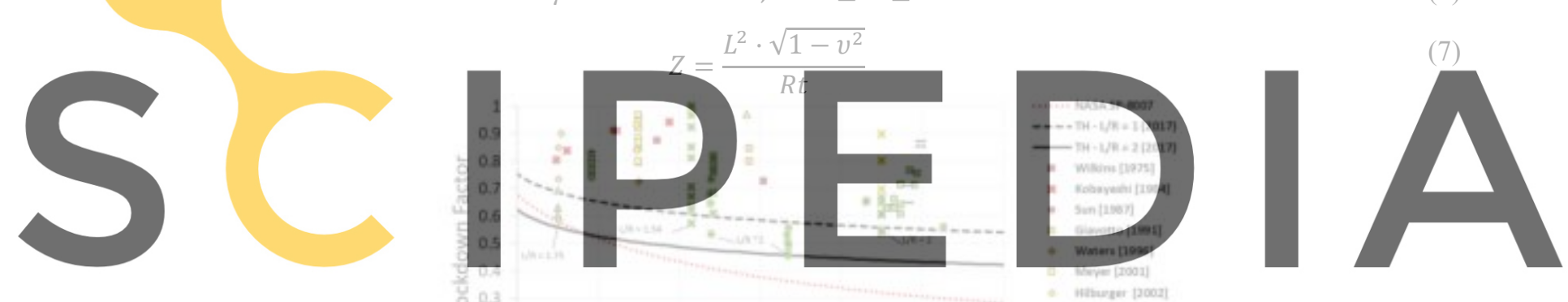

Register for free at https//www.scipedia.com to download the version without the watermark

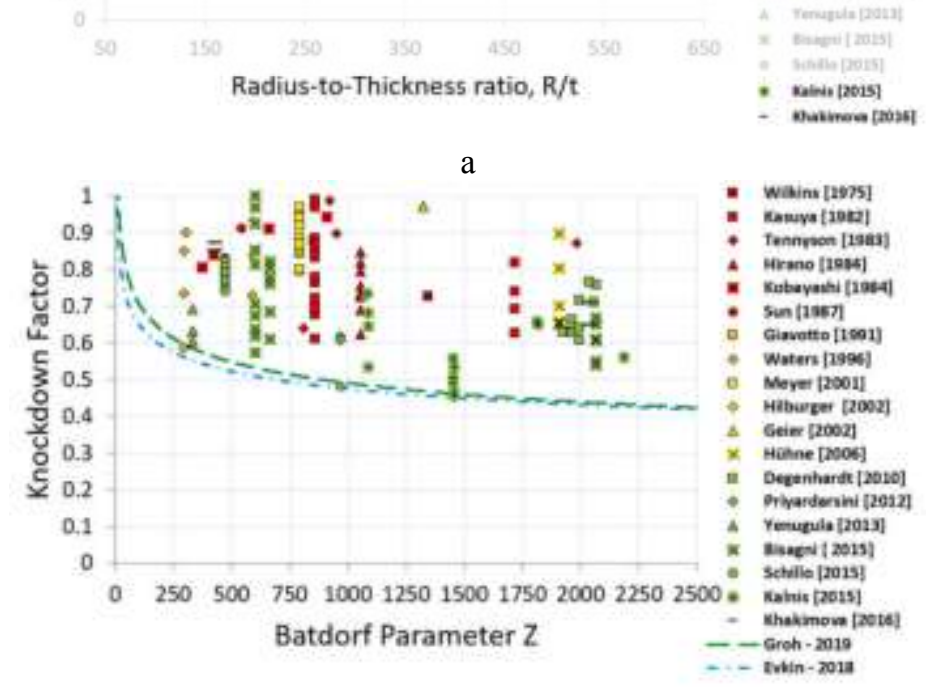

$\mathrm{b}$

Figure 1: Knockdown factors of axially compressed cylinders for different $R / t$ ratios (a) and different Batdorf Parameter Z (b)[5] 
Finite element analysis is the most popular method to study imperfection sensitivity. In order to acquire knockdown factors, shape imperfections need to be introduced into numerical model. Up to now, there are several methods to establish the imperfections. For example, buckling mode shape can be firstly calculated by eigenvalue analysis and then be introduced into finite element model. Mode shape corresponding to the first eigenvalue is usually used. However, the stiffness would be largely weakened. Some people proposed single perturbation load approach (SPLA)[6] and multiple perturbation load approach (MPLA)[7]. Hao[8] combined MPLA with an optimization framework, and then proposed the worst multiple perturbation load approach (WMPLA). The WMPLA has been successfully validated by stiffened cylinder experiments[9].

Although the imperfection of cylinders has been frequently researched, there are seldom comparison between different stiffener modes. There are also few axial compression experiments for large scale cylinder. In this paper, orthogrid stiffened cylinder and isogrid stiffened cylinder are compared and researched through numerical and experimental methods.

\section{STIFFENED CYLINDERS AND IMPERFECTION MODE IN NUMERICAL} MODEL

Based on finite element methods, three kinds of cylinders are carefully researched and compared, including unstiffened cylinder, orthogrid cylinder and isogrid cylinder. They have the same radius $R=1500 \mathrm{~mm}$, the same height $H=1500 \mathrm{~mm}$ and the same skin thickness $t_{s}=$ $2.5 \mathrm{~mm}$. The height of stiffener $h$ is adjusted to research the influence brought by mass balance

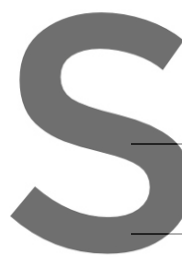
coefficient $m_{b}$. All the

Distance of vertical stiffener

Distance of horizontal stiffener

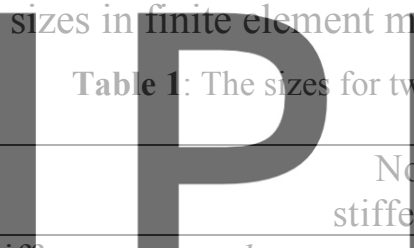

$b_{s}$

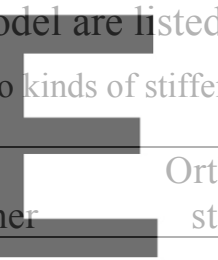

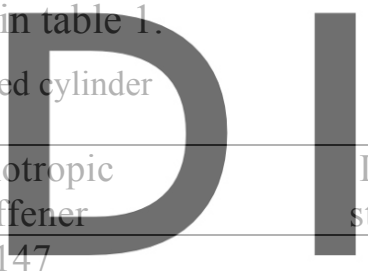

300

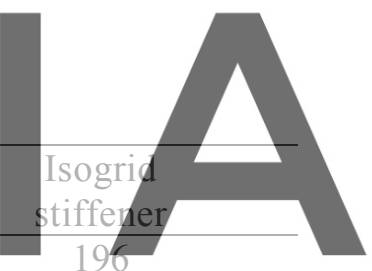

96

Register for freeicatidstapstifwetw.scipediah,om to download the version without the watermark \begin{tabular}{lllllllllll} 
Height of stiffener & $h$ & - & 2.5 & 5 & 10 & 20 & 2.5 & 5 & 10 & 20 \\
\hline
\end{tabular}

$\begin{array}{rllllllllll}\text { Mass balance between stiffener and skin } & m_{b} & 0 & 0.05 & 0.1 & 0.2 & 0.4 & 0.05 & 0.1 & 0.2\end{array}$ function is used to describe the imperfection.

$$
w(x, \theta)=a \cdot \sin \left(\frac{2 \pi m x}{H}\right) \cdot \sin (n \theta)
$$

where, $a$ is the imperfection amplitude; $m$ and $n$ is the wave length number along vertical direction and circumferential direction. In order to ensure that the wave length along vertical and circumferential directions is the same, $\mathrm{n}$ is always 6 times $\mathrm{m}$. Using Python script in ABAQUS, the function can be easily applied to modify the coordinates of nodes in numerical model. Seven kinds of arrangements of three parameters are listed in Table 2, and some are explicitly given in Figure 2. 
Table 2: Imperfection parameters adopted in FEM for cylinders

\begin{tabular}{cccccccccc}
\hline \multirow{2}{*}{ Variables } & \multirow{2}{*}{ Unit } & & \multicolumn{7}{c}{ Case ID } \\
\cline { 4 - 10 } & & & 1 & 2 & 3 & 4 & 5 & 6 & 7 \\
\hline Imperfection amplitude & $a$ & $\mathrm{~mm}$ & 2.5 & 5 & & 10 & & 20 \\
\hline Wave number along vertical direction & $m$ & - & & 4 & & 1 & 2 & 3 & 4 \\
\hline $\begin{array}{c}\text { Wave number along circumferential } \\
\text { direction }\end{array}$ & $n$ & - & & 24 & & 6 & 12 & 18 & 24 \\
\hline
\end{tabular}

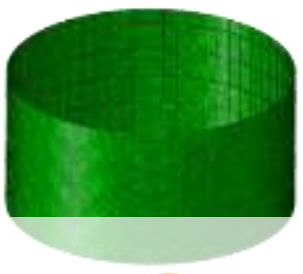

Case 1

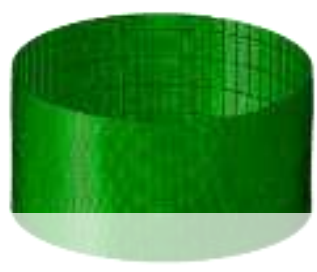

b Case 4

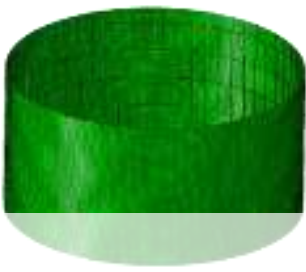

c Case 5

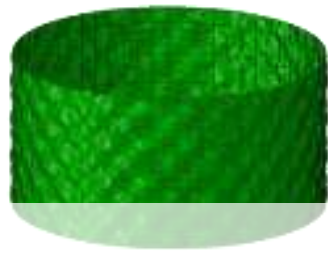

d Case 7

Figure 2: Several imperfection modes for isogrid stiffened cylinders

\section{INFLUENCE BY IMPERFECTIONS FOR THREE KINDS OF CYLINDERS}

3.1 Mechanical behaviors of three kinds of cylinders

Firstly, unstiffened

can be easily deduced to
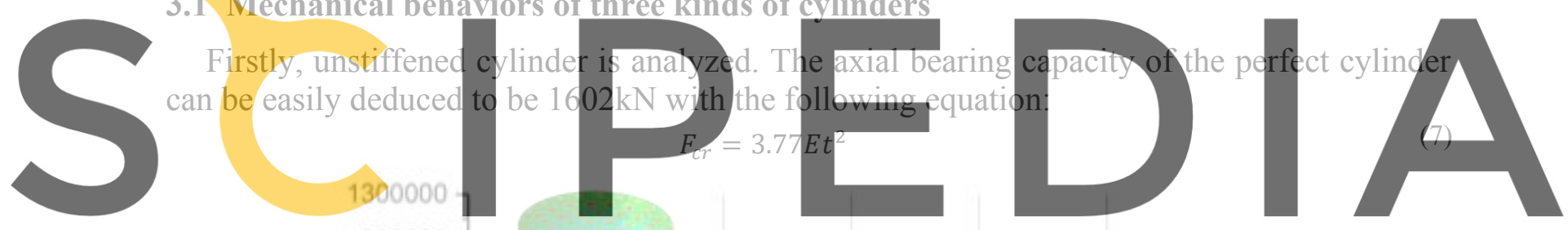

Register for free at https//www.scipedia.com to download the version without the watermark

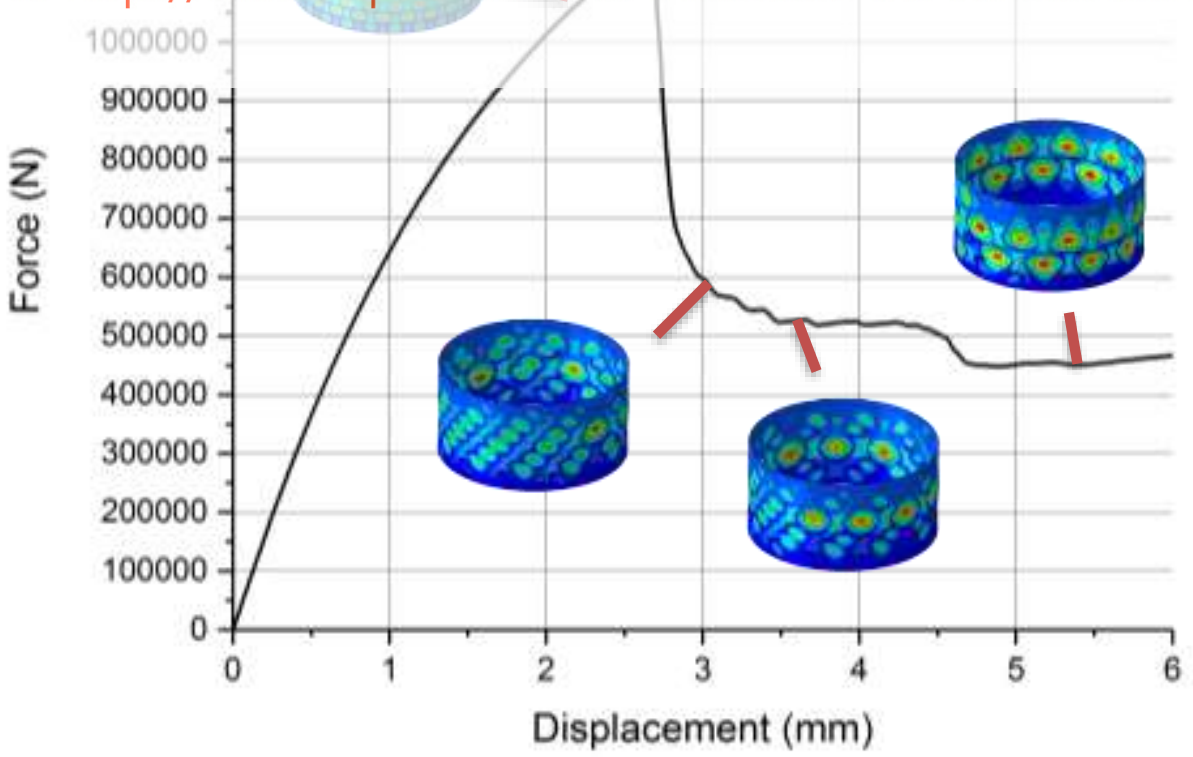

Figure 3: Force-displacement curves for unstiffened cylinder with imperfection amplitude $a=2.5 \mathrm{~mm}$ 
The force-displacement curves for different imperfections are almost the same, and four stages are included. Taking the curve for imperfection amplitude $a=2.5 \mathrm{~mm}$ as example (Figure 3 ), there are some local bending deformation in pre-buckling stage, and they appear in the skins between the adjacent stiffeners. The bearing capacity is $1165 \mathrm{kN}$, and knockdown factor is 0.73 . Stage 2, 3 and 4 are post-buckling stages. In stage $2(u=2.6 \mathrm{~mm} \sim 3.1 \mathrm{~mm})$, the load suddenly drops from $1170 \mathrm{kN}$ to $570 \mathrm{kN}$, and the deformation changes into shear band. In Stage 3, shear band retains, and meanwhile a wave appears in the middle of the cylinder. In Stage 4, the load drops again, and two waves appear along the axial direction of the cylinder.

Figure 4 gives the force-displacement curve for orthogrid stiffened cylinder with parameters $h=5 \mathrm{~mm}, a=2.5 \mathrm{~mm}$ and $m=4$. For this stiffened cylinder, there are also some local bending deformation in pre-buckling stage, but they are weaker than that in unstiffened cylinder. Three Post-buckling stages is almost the same as that in unstiffened cylinder. However, More load suddenly drops between stage 2 and stage 3 because of the stiffeners. Much more energy is released during the transition of deformation modes.

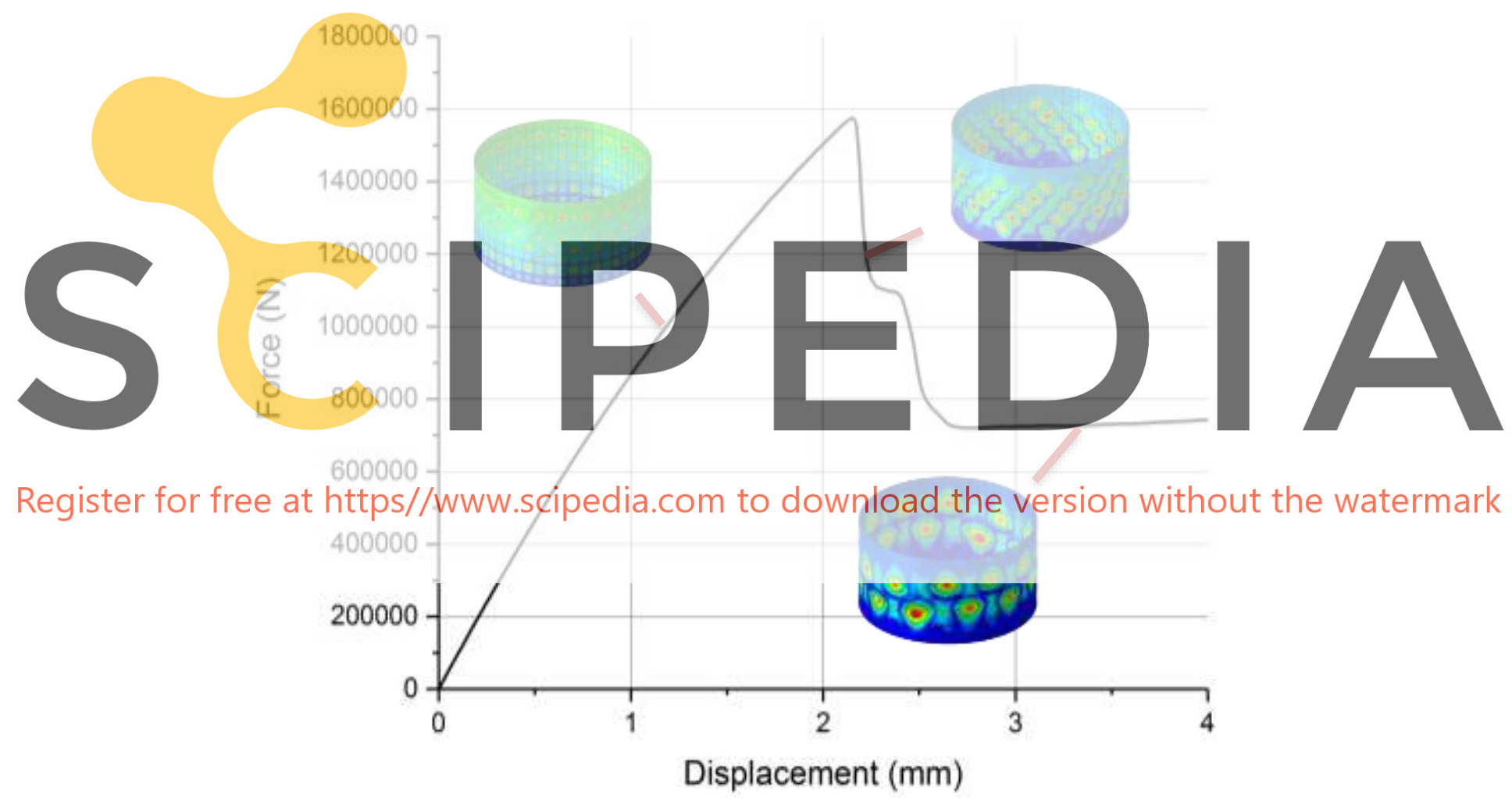

Figure 4: Force-displacement curve for orthogrid stiffened cylinder with parameters $h=5 \mathrm{~mm}, a=2.5 \mathrm{~mm}$ and $m$ $=4$

Figure 5 lists the force-displacement curves for orthogrid stiffened cylinder with different imperfections. When $m$ is 4, its stiffness becomes weaker with increasing imperfection amplitude. Bearing capacity generally becomes weaker for the larger amplitude. However, when the amplitude becomes from $10 \mathrm{~mm}$ to $20 \mathrm{~mm}$, it is getting a little larger. When the imperfection amplitude is $10 \mathrm{~mm}$, the cylinder stiffness is almost the same in case that $\mathrm{m}=1$ and no imperfection, and becomes weaker for $\mathrm{m}=2 \sim 4$. However, all the bearing capacities 
are almost the same, and $m=2$ is the worst case. Moreover, for all the cases, lower bounded loads are almost the same, varying from $110 \mathrm{kN}$ to $140 \mathrm{kN}$.
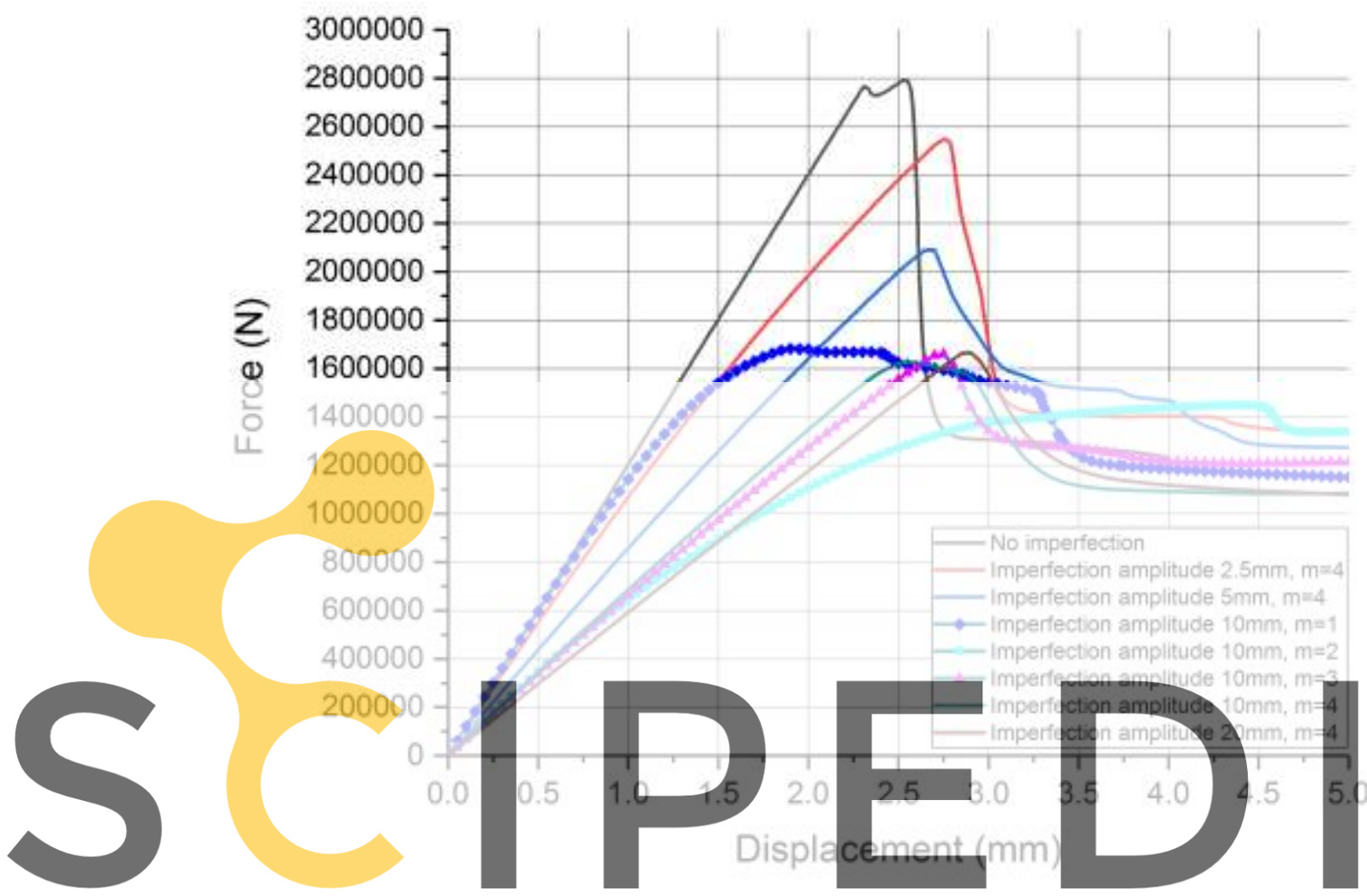

Figure 5: Force-displacement curves for orthogrid stiffened cylinder with different imperfection amplitudes Register for free at https//WwW.scipedia.com to download the version without the watermark

Figure 6 gives the force-displacement curve for isogrid stiffened cylinder with parameters $h$ $=10 \mathrm{~mm}, a=10 \mathrm{~mm}$ and $m=4$. For this stiffened cylinder, there are also some local bending deformation in pre-buckling stage. However, only two post-buckling stages can be observed. One is the transition stage from $1690 \mathrm{kN}$ to $890 \mathrm{kN}$, the other is another local bending deformation. 


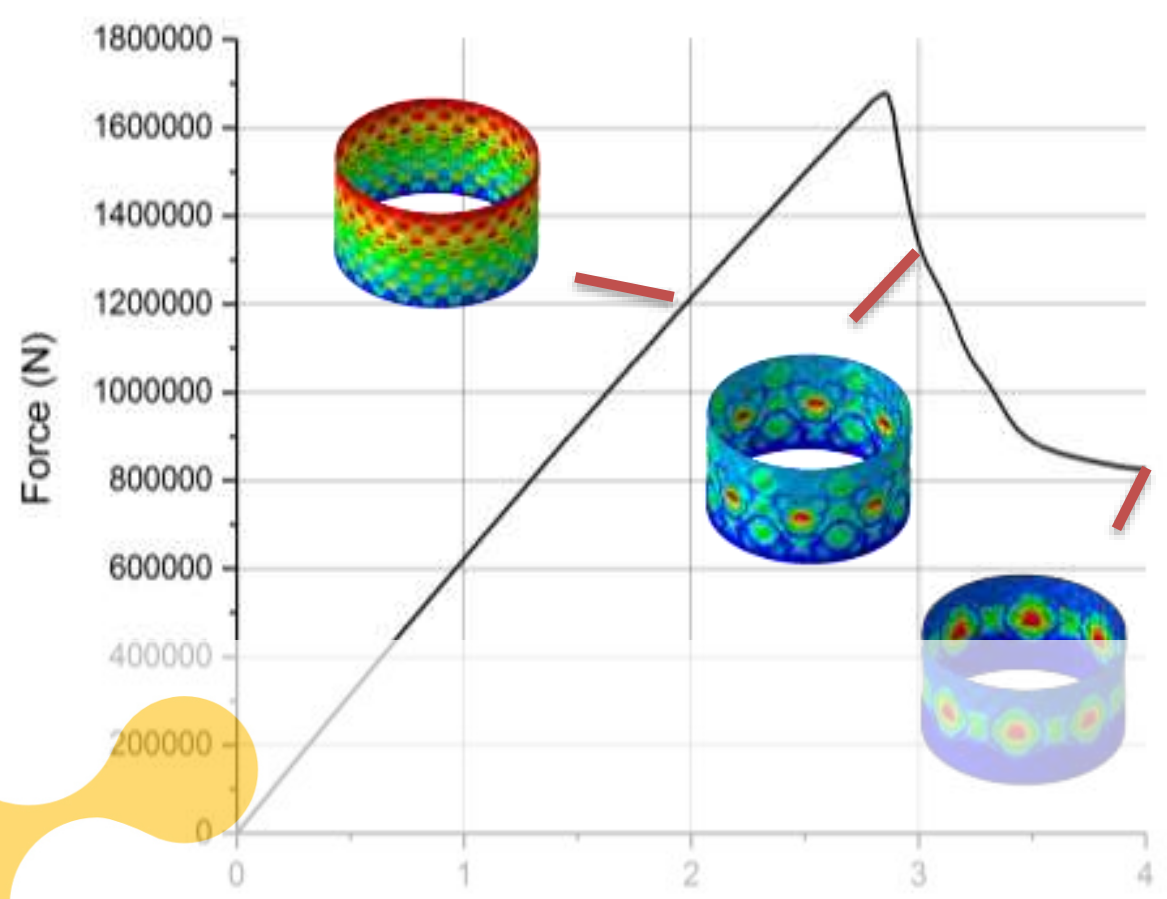

Displacement (mm)

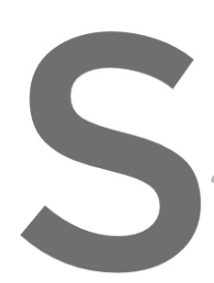

Figure 6: Force-displac

4.2 Comparisom of kn
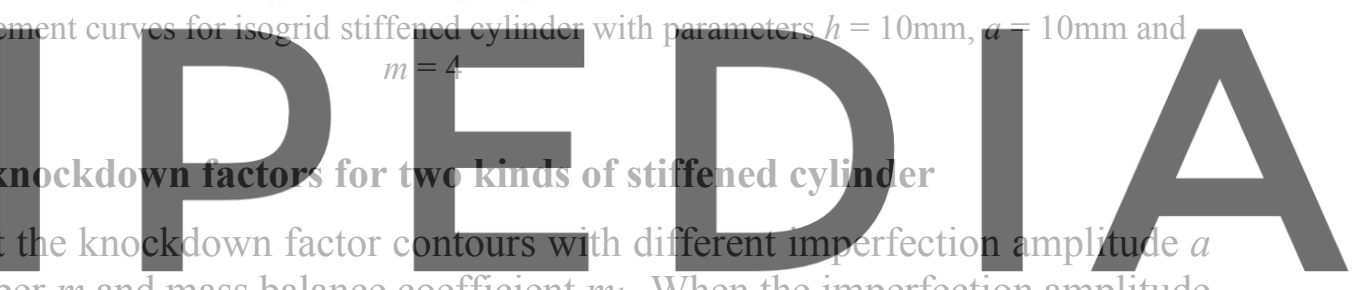

and wave length number $m$ and mass balance coefficient $m_{b}$. When the imperfection amplitude

Register for lower than $5 \mathrm{~mm}$, the bearing capacity is much sensitive to $m_{b}$. Meanwhile in Figure 7 red ${ }^{2}$. area for isogrid cylinder is larger than that for orthogrid cylinder, which means that isogrid

cylinder has a little higher knockdown factor than orthogrid cylinder. $m=2$ is the worst wave length number for both kinds of cylinders, and this is possibly because the length-radius-radio is suitable to produce this wave number.

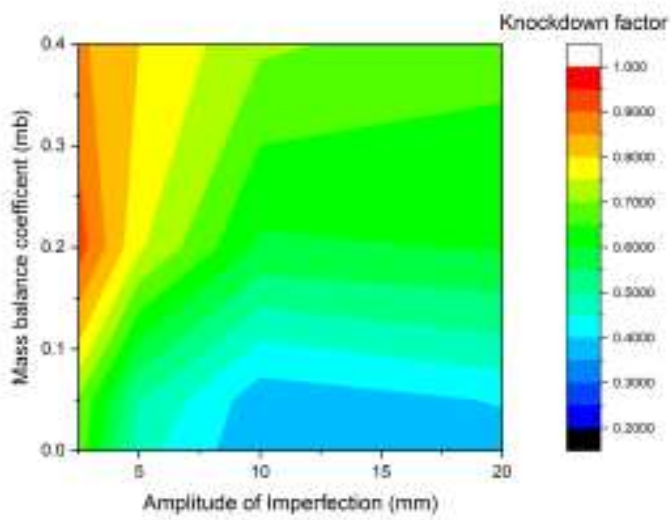

a Orthogrid stiffened cylinder

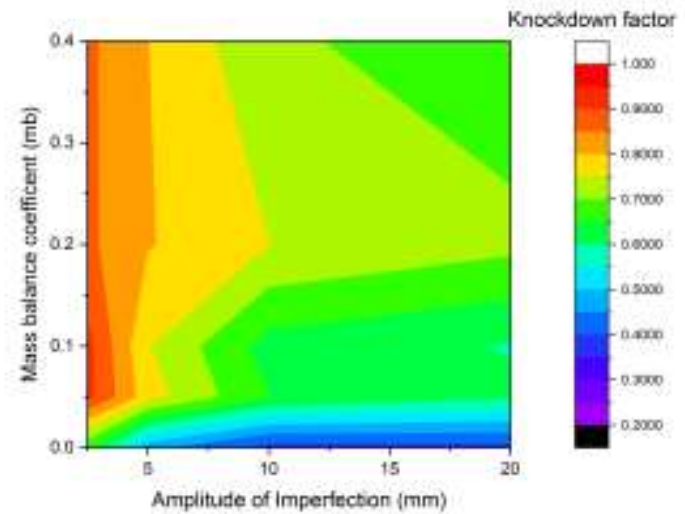

$\mathrm{b}$ Isogrid stiffened cylinder

Figure 7: Knockdown factor .vs. imperfection amplitude for two kinds of cylinders 


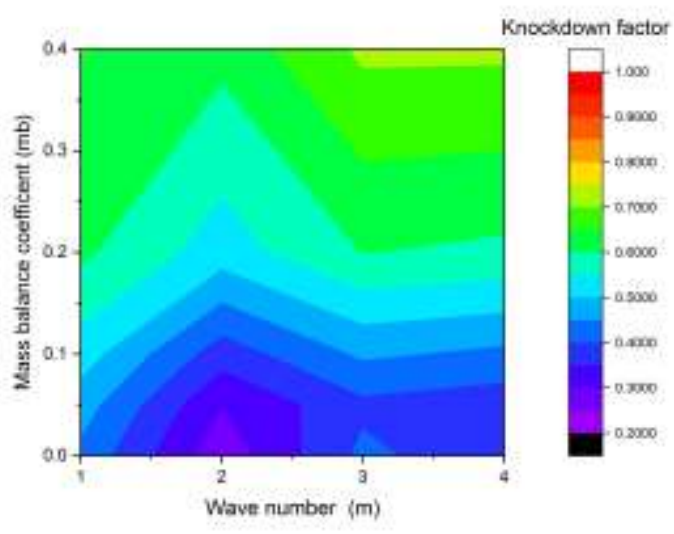

a Orthogrid stiffened cylinder

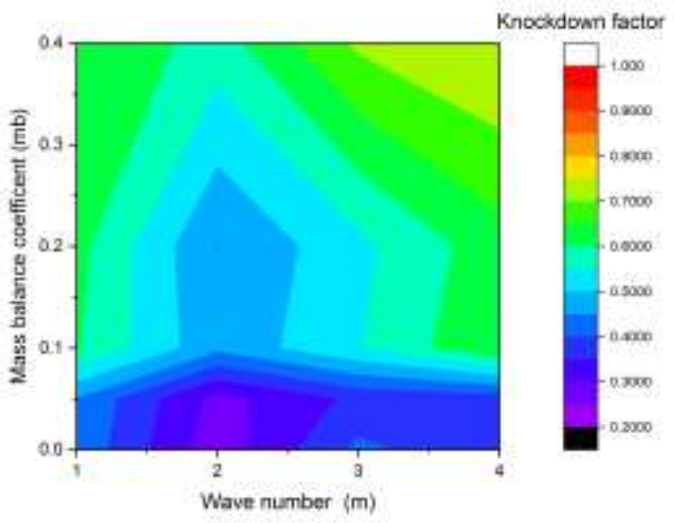

b Isogrid stiffened cylinder

Figure 8: Mass balance coefficient $\mathrm{mb}$.vs. wave number $\mathrm{m}$ for two kinds of cylinders

Figure 9 compares critical loads of two kinds of stiffened cylinder. Although isogrid stiffened cylinder is less sensitive to manufacturing imperfection, it has lower critical load. The reason is simple. The skin area between adjacent stiffeners is larger in isogrid cylinder, resulting in more easily skin buckling. For the same stiffener height $\mathrm{h}=10 \mathrm{~mm}$, linear eigenvalue algorithm proves that skin buckling doesn't appear in orthogrid cylinder but in isogrid cylinder, as shown in Figure 10. Skin buckling can decrease the critical load of perfect isogrid cylinder,

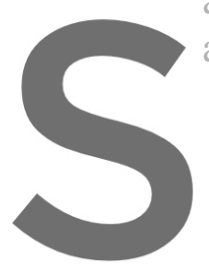
and of course increas
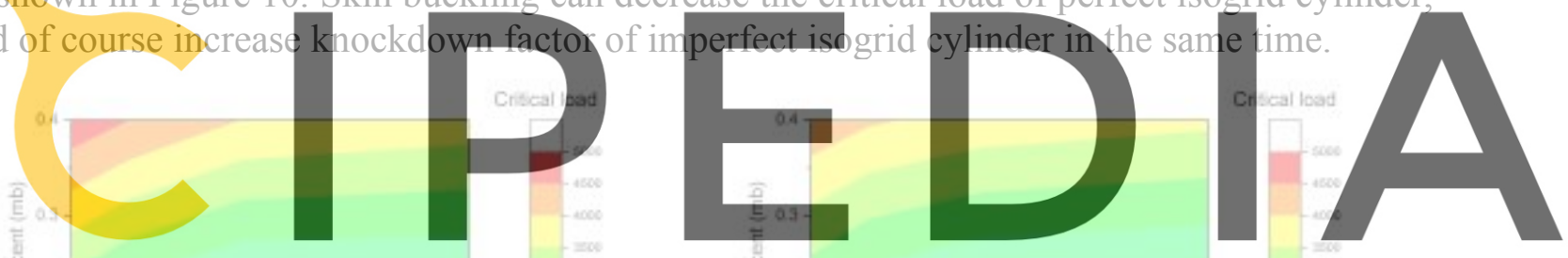

Register for free at https//www.scipedia.com to download the version without the watermark

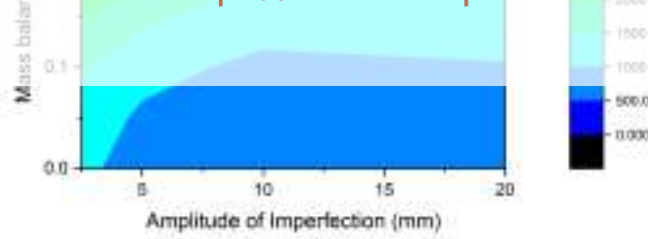

a Orthogrid stiffened cylinder

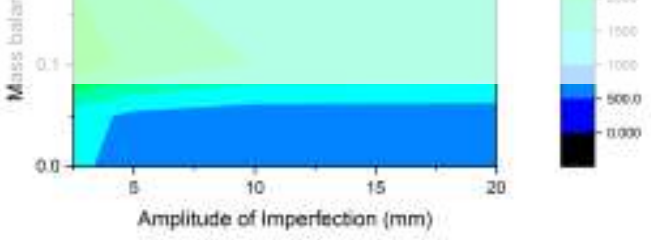

b Isogrid stiffened cylinder

Figure 9: Mass balance coefficient mb .vs. imperfection amplitude for two kinds of cylinders 


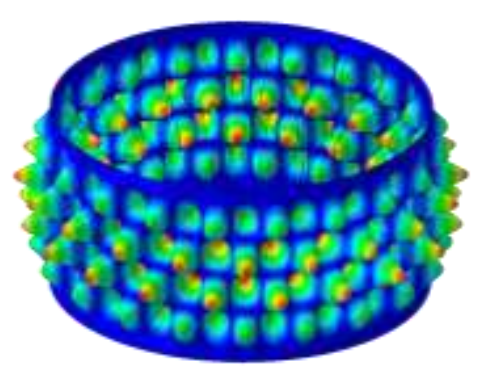

a Orthogrid stiffened cylinder with $\mathrm{h}=10 \mathrm{~mm}$

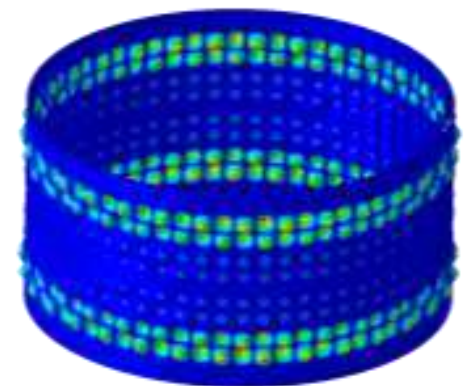

b Orthogrid stiffened cylinder with $\mathrm{h}=20 \mathrm{~mm}$

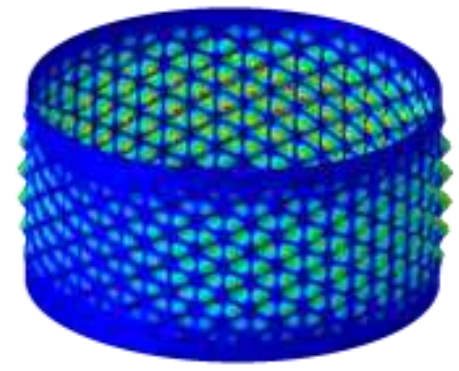

c Isogrid stiffened cylinder witht $\mathrm{h}=10 \mathrm{~mm}$

Figure 10: Buckling modes corresponding to first eigenvalue for different cylinders

\subsection{Suggested criterion to choose knockdown factor}

Knockdown factor is an important parameter in weak-stiffened cylinder. It should be used with "factor of safety" (FOS) in aerospace engineering. The latter is also to describe the error between failure load and allowable load caused by the errors of material, structure sizes and load. It is not necessary to choose too conservative knockdown factor. A new criterion is suggested in this part. The knockdown factors can be recorded based on different imperfection,

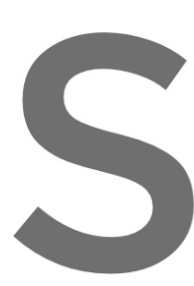
and their statistics resulit can be

unstiffened, i.e., when $m_{b} \leqslant 0$. 0.2 , the suggested knock
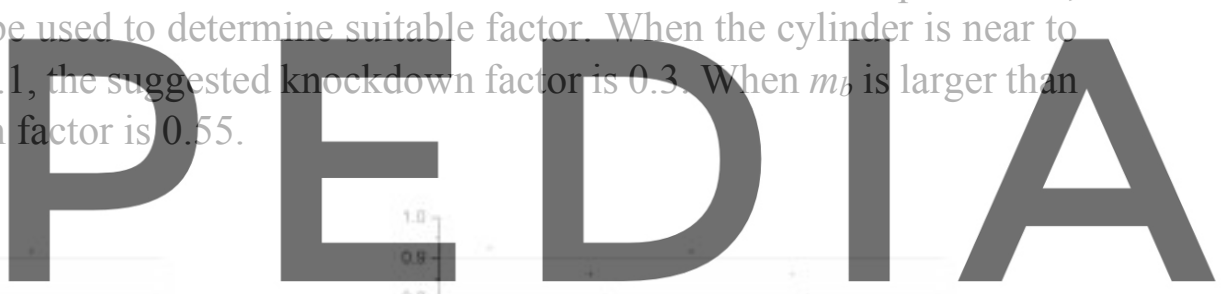

Register for free at https//www.scipedia.com to download the version without the watermark

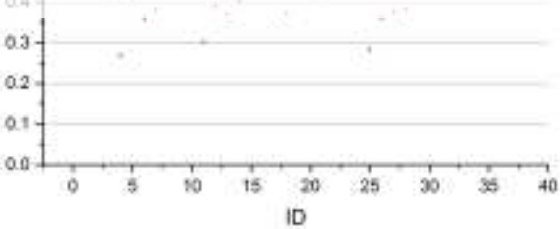

$\mathrm{a} \mathrm{mb} \leqslant 0.1$

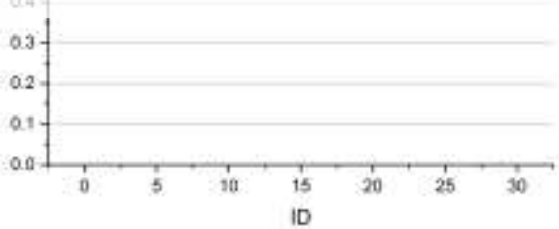

$\mathrm{b} \mathrm{mb}>0.2$

Figure 11: Knockdown factors for all the simulation cases

\section{AXIAL COMPRESSION EXPERIMENTS FOR GRID-STIFFENED CYLINDERS}

In order to obtained actual knockdown factor, axial compression experiments of two stiffened cylinders are operated. One is an isogrid stiffened cylinder with $m_{b}=0.16$, another is an orthogrid stiffened cylinder with $m_{b}=0.75$.

For the isogrid stiffened cylinder, two numerical methods are applied, including linear eigenvalue method and nonlinear implicit method. In the latter method, different imperfection 
amplitudes are considered. There is well agreement on failure modes between simulation and experiment. When the imperfection $a=1.5 \mathrm{~mm}$ is introduced, the critical load is very closed to that in experiment. However, the knockdown factor can be up to 0.75 . This value is much higher than the suggested value 0.55 in Part 4.2, but is much near to the average value 0.6 0.7 in Figure $11 b$.
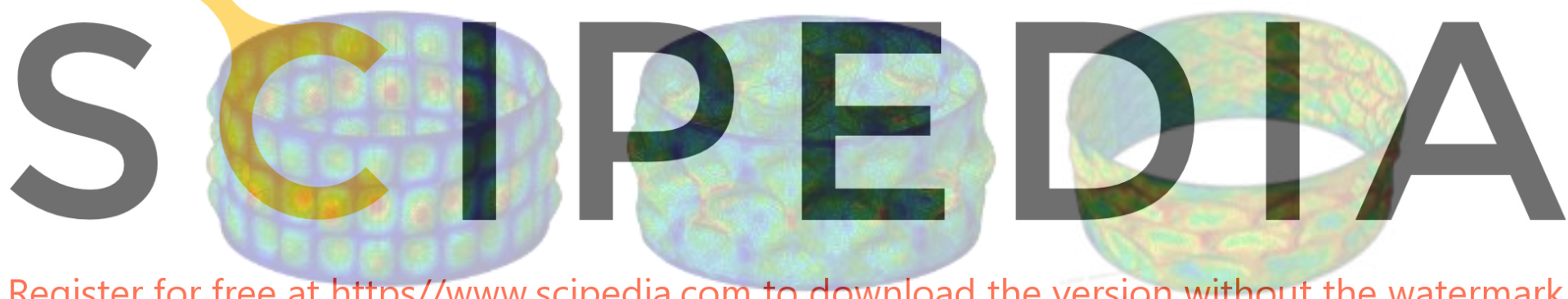

Register for free at https//www.scipedia.com to download the version without the watermark

a Eigenvalue

b Nonilinear, $a=0$

c Nonlinear, $a=1.5 \mathrm{~mm}$

Figure 13: Failure mode in simulation of orthogrid stiffened cylinder

Table 3: Example of the construction of one table

\begin{tabular}{|c|c|c|c|c|}
\hline \multirow{2}{*}{ Method } & \multirow{2}{*}{$\begin{array}{l}\text { Imperfection amplitude } \\
\qquad / \mathrm{mm}\end{array}$} & \multicolumn{2}{|c|}{ Critical load $/ \mathrm{kN}$} & \multirow{2}{*}{ Error } \\
\hline & & Experiment & Simulation & \\
\hline Eigenvalue & - & \multirow{4}{*}{4293} & 5720 & $25.0 \%$ \\
\hline \multirow{3}{*}{ Nonlinear } & 0 & & 5745 & $25.3 \%$ \\
\hline & 1 & & 4654 & $7.7 \%$ \\
\hline & 1.5 & & 4119 & $-4.2 \%$ \\
\hline
\end{tabular}

For the orthogrid stiffened cylinder, the knockdown factor is up to 0.92 , which is much closed to 1 . It means that the cylinder is not sensitive to manufacturing imperfection anymore. For the stiffened cylinders with higher $m_{b}$, the imperfections can be ignored. 


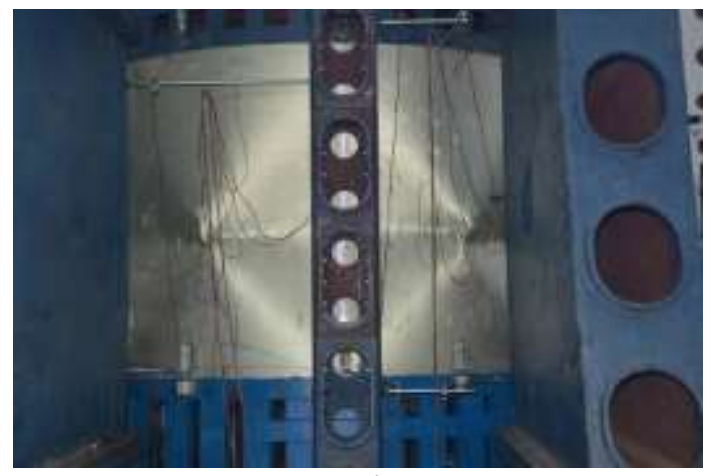

a Experiment

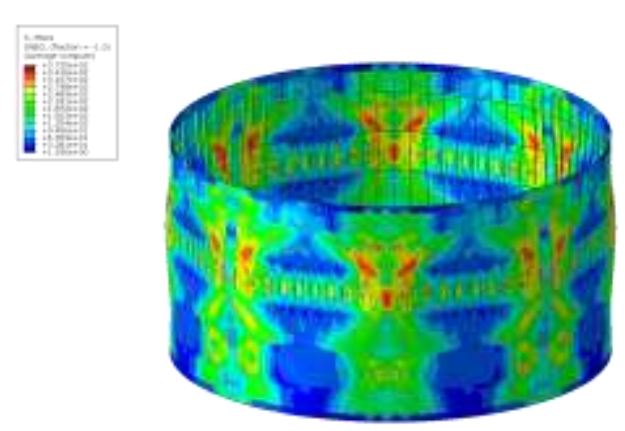

b Simulation

Figure 14: Page layout

Table 4: Example of the construction of one table

\begin{tabular}{cccc}
\hline \multirow{2}{*}{ Method } & \multicolumn{2}{c}{ Critical load $/ \mathrm{kN}$} & \multirow{2}{*}{ Error } \\
\cline { 2 - 3 } & Experiment & Simulation & \\
\hline Nonlinear & 6835 & 6320 & $8.1 \%$ \\
\hline
\end{tabular}

\section{CONCLUSIONS}

In order to investigate the influence of manufacturing imperfection on axially compressed cylinder, three kinds of cylinders are compared using finite element methods, including unstiffened cylinder, orthogrid stiffened cylinder and isogrid stiffened cylinder. The bidirectional sinusoidal imperfection is introduced, and different imperfection parameters are introduced. Two compression experiments are also compared. Some useful conclusions can be obtained:

- Generally, the bearing capacity of the cylinder becomes weaker with larger imperfection. But sometimes, it can get a little larger.

- $\quad m=2$ is the most dangerous imperfection wave number for the cylinder with $R=H=$ $1500 \mathrm{~mm}$.

- $\quad$ Lower bounded loads are almost the same for all the imperfections.

- $\quad$ Compared with orthogrid cylinders, isogrid cylinders have a little higher knockdown factor, but have a little lower critical load.

- $\quad$ For $m_{b} \leqslant 0.1$, the knockdown factor is suggested as 0.3 ; for $m_{b} \geqslant 0.2$, the knockdown factor is suggested as 0.55 .

- Axial compression experiment proves that the weak-stiffened cylinder is sensitive to manufacturing imperfection, and the influence of imperfection almost can be ignored when $m_{b}$ exceeds 0.75 .

\section{REFERENCES}

[1] Peterson, J.P., Seide, P. and Weingarten, V.I. Buckling of Thin-Walled Circular Cylinders, NASA SP-8007, Technical Report, (1968).

[2] Wagner, H.N.R., Hühne, C. and Niemann, S. Robust knockdown factors for the design of axially loaded cylindrical and conical composite shells - Development and Validation. 
Composite Structures (2017) 173: 281-303.

[3] Wagner, H.N.R., Hühne, C., Niemann, S. and Khakimova R. Robust design criterion for axially loaded cylindrical shells - Simulation and Validation. Thin-Walled Structures (2017) 115: $154-162$.

[4] Evkin, A. Local buckling of cylindrical shells. Pogorelov's geometrical method. in Andrianov I., Manevich A., Mikhlin Y., Gendelman O. (eds) Problems of Nonlinear Mechanics and Physics of Materials. Advanced Structured Materials, vol. 94. Springer, Cham, (2019).

[5] Wagner, H.N.R., Hühne, C. and Niemann, S. Buckling of launch-vehicle cylinders under axial compression: A comparison of experimental and numerical knockdown factors. ThinWalled Structures. (2020) 155: 106931.

[6] Hühne, C., Rolfes, R., Breitbach, E. and Teßmer, J. Robust design of composite cylindrical shells under axial compression - Simulation and validation. Thin-Walled Structures (2008) 46(7): 947-62.

[7] Arbelo, M.A., Degenhardt, R. Castro, S.G.P. and Zimmermann R. Numerical characterization of imperfection sensitive composite structures. Composite Structures (2014) 108: 295-303.

[8] Hao, P., Wang, B., Li, G., Meng, Z., Tian, K., Zeng, D. and Tang, X. Worst Multiple Perturbation Load Approach of stiffened shells with and without cutouts for improved knockdown factors. Thin-Walled Structures (2014) 82: 321-330.

[9] Wang, B., Du, K., Hao, P., Zhou, C., Tian, K., Xu, S., Ma, Y. and Zhang, X. Numerically and experimentally predicted knockdown factors for stiffened shells under axial compression. Thin-Walled Structures (2016) 109: 13-24. 